\title{
Anti-inflammatory effect of tricin isolated from Alopecurus aequalis Sobol. on the LPS-induced inflammatory response in RAW 264.7 cells
}

\author{
BYOUNG-MAN KANG ${ }^{1}$, BYOUNG-KWAN AN ${ }^{1}$, WON-SEOK JUNG ${ }^{1}$, HO-KYUNG JUNG ${ }^{1}$, \\ JUNG-HEE CHO $^{1}$, HYUN-WOO CHO ${ }^{1}$, SE JI JANG ${ }^{2}$, YOUNG BEOM YUN ${ }^{2}$ and YONG IN KUK ${ }^{2}$
}

${ }^{1}$ Division of Traditional Korean Medicine Resource, National Development Institute of Korean Medicine, Jangheung 59338;

${ }^{2}$ Department of Development in Oriental Medicine Resources, College of Life Science and Natural Resources, Sunchon National University, Sunchon 57922, Republic of Korea

Received January 11, 2016; Accepted September 23, 2016

DOI: $10.3892 / \mathrm{ijmm} .2016 .2765$

\begin{abstract}
The aim of this study was to identify major antiinflammatory compounds in Alopecurus aequalis Sobol. (A. aequalis). The ethanol extract and the hexane-, dichloromethane-, ethyl acetate- and $n$-butanol-soluble fractions derived from A. aequalis were evaluated in order to determine their inhibitory effects on nitric oxide (NO) production in RAW 264.7 cells stimulated with lipopolysaccharide (LPS). The ethanol extract decreased NO production in a dosedependent manner without any evidence of cytotoxicity at a concentration range of $0-200 \mu \mathrm{g} / \mathrm{ml}$. The ethyl acetate soluble fraction was the most potent among the four soluble fractions. A compound was isolated by reversed-phase high-performance liquid chromatography from the ethyl acetate soluble fraction and this was identified to be tricin. Tricin inhibited the LPS-induced NO production in a dose-dependent manner without any evidence of cytotoxity at a concentration range of $1-100 \mu \mathrm{g} / \mathrm{ml}$. Tricin also inhibited the LPS-induced production of prostaglandin $\mathrm{E}_{2}$. Western blot analysis indicated that tricin decreased the LPS-induced increase in the protein levels of inducible NO synthase and cyclooxygenase. In addition, tricin suppressed the production of intracellular reactive oxygen species in the LPS-stimulated RAW 264.7 cells, as measured by flow cytometry. Taken together, our results clearly indicate that tricin is a major functional anti-inflammatory compound which can be isolated from A. aequalis extracts.
\end{abstract}

Correspondence to: Professor Yong In Kuk, Department of Development in Oriental Medicine Resources, College of Life Science and Natural Resources, Sunchon National University, 255 Jungang-ro, Sunchon 57922, Republic of Korea

E-mail: yikuk@sunchon.ac.kr

Key words: Alopecurus aequalis Sobol., lipopolysaccharide, inflammation, medicinal plant, tricin

\section{Introduction}

Alopecurus aequalis Sobol. (A. aequalis) is an annual or biennial herb that belongs to the Gramineae family. It is a dominant resource that grows in winter, and is commonly found in Korean wetlands and rice fields. Four Alopecurus species have been reported in Korea: Alopecurus aequalis, Alopecurus myosuroides Huds., Alopecurus paratensis L. and Alopecurus japonicus Steud. Among these, A. myosuroides, A. paratensis, and A. japonicus are indigenous plants, whereas A. aequalis is an endemic species $(1,2)$.

A. aequalis is a weed that causes problems during the cultivation of barley during winter. A. aequalis accounts for $95 \%$ of all weeds growing during barley cultivation $(3,4)$. Moreover, A. aequalis grows before the harvesting of rice, and can compete against the crop. Thus, it causes the most damage when cultivating barley in rice fields as an aftercrop $(5,6)$. A. aequalis sprouts and roots reproduce from nodes on the ground, even after trimming by plowing or the harrowing of fields.

Although the eradication of A. aequalis has been well studied, research evaluating the utilization of $A$. aequalis is limited, with the exception of its use in cover crop research $(7,8)$. Additionally, there is no known use for A. aequalis plants in food or medicine.

However, A. aequalis has been used as an effective treatment for anasarca, chickenpox, stomachache and diarrhea (9). As it has been used to treat inflammatory diseases, such as anasarca and diarrhea, and active bacterial diseases, we hypothesized that A. aequalis may exhibit anti-inflammatory activity.

Inflammation is a defensive response produced by bioorganisms against external stimuli, including toxic substances, chemical stimulation and bacterial infection. Dysregulated inflammatory responses promote mucosal damage, thereby promoting the development of various diseases, including cancer $(10,11)$. Lipopolysaccharide (LPS), an outer-membrane component of Gram-negative bacteria, triggers diverse reactions, including local inflammation, antibody production and septicemia (12). Macrophages respond to the early stages of LPS infection, playing a central role in host defense and the maintenance of homeostasis. However, high concentrations of 
LPS can induce the secretion of pro-inflammatory mediators from macrophages, including tumor necrosis factor- $\alpha$ (TNF- $\alpha$ ), interleukin (IL)-1 $\beta$, IL-6 and nitric oxide (NO), leading to host fatality (13-15). NO is generally produced by inducible NO synthase (iNOS) when macrophages are activated, and has an antibacterial effect that inhibits several viruses and parasites (16). However, the excessive production of NO is known to induce inflammation, tissue damage, genetic mutation and nerve damage $(17,18)$. The expression of proinflammatory cytokines, such as TNF- $\alpha$, IL-1 $\beta$ and IL-6 is regulated by mitogen-activated protein kinases (MAPKs), including extracellular signal-regulated kinase 1/2 (ERK1/2), p38 kinase (p38), c-Jun NH2-terminal kinase (JNK) and nuclear factor $-\kappa \mathrm{B}(\mathrm{NF}-\kappa \mathrm{B})(19)$. In particular, $\mathrm{NF}-\kappa \mathrm{B}$ plays an important role in the expression of immunity-associated and inflammatory genes (20). The dissociation of the inhibitor of $\kappa \mathrm{B}-\alpha(\mathrm{I} \kappa \mathrm{B}-\alpha)$, which binds and inhibits $\mathrm{NF}-\kappa \mathrm{B}$, allows for the activation and translocation of $\mathrm{NF}-\kappa \mathrm{B}$ from the cytoplasm to the nucleus to act as a transcription factor for cytokines, including TNF- $\alpha$, IL-12 and IL-6 $(21,22)$.

The aim of this study was to identify the major compounds involved in the anti-inflammatory activity of A. aequalis through bioassay-guided fractionation. We examined the effects of the ethanol (EtOH) extract from A. aequalis and its different solvent-soluble fractions on the production of the proinflammatory mediator, NO, using RAW 264.7 macrophages. The most active fraction was further fractionated to identify the active compounds. The major components were identified by high-performance liquid chromatography (HPLC) and NMR spectra, and the anti-inflammatory activity of the individual components was confirmed by measuring the production of inflammatory mediators, the protein expression of enzymes involved in their production and the scavenging of reactive oxygen species (ROS) in LPS-stimulated macrophages.

\section{Materials and methods}

Plant material. A. aequalis was collected from an open field located at Jangheung (latitude, 34.68; longitude, 126.90), Jeollanamdo, Korea, in May 2014. A voucher specimen (TKM2014-55) has been deposited at the Medicinal Crop Seed Supply Center, Jeollanamdo Development Institute of Traditional Korean Medicine, Republic of Korea.

General procedures. Optical rotations were measured on a Jasco P-1020 polarimeter in EtOH (Jasco, Easton, MD, USA). UV spectra were recorded using a Shimadzu UV-1601 UV-Visible spectrophotometer (Shimadzu, Tokyo, Japan). High resolution fast-atom bombardment (HR-FAB) and electrospray ionization (ESI) mass spectra were obtained on a LC/MS IT-TOF hybrid mass spectrometer (Shimadzu). NMR spectra, including COSY, HMQC and HMBC experiments were recorded on a Varian NMR System $600 \mathrm{MHz}$ (Agilent Technologies, Inc., Santa Clara, CA, USA) NMR spectrometer with chemical shifts given in ppm (Varian, Palo Alto, CA, USA). Preparative HPLC (Agilent Technologies, Inc.) was conducted using a Gilson 306 pump (Gilson, Middleton, WI, USA) with a diode array index detector (DAD). Silica gel 60 and RP-C18 silica gel (230-400 mesh; Merck, Darmstadt, Germany) were used for column chromatography. The packing material for molecular sieve column chromatography was Sephadex LH-20 (Sigma, St. Louis, MO, USA). Spots were detected by thin layer chromatography (TLC) under UV light or by heating after spraying with $10 \% \mathrm{H}_{2} \mathrm{SO}_{4}$ in $\mathrm{C}_{2} \mathrm{H}_{5} \mathrm{OH}(\mathrm{v} / \mathrm{v})$.

Extraction and isolation. A. aequalis $(2.0 \mathrm{~kg}$ shoot dry weight) were extracted with $95 \% \mathrm{EtOH}$ (3x60 liters) at room temperature for $3 \mathrm{~h}$. The ethanol extract was concentrated under reduced pressure to yield the ethanol extract (392 g). The concentrated ethanol extract was then suspended in $\mathrm{H}_{2} \mathrm{O}$ (2.0 liters) and partitioned successively to the $n$-hexane- (75 g), dichloromethane $\left(\mathrm{CH}_{2} \mathrm{Cl}_{2}-; 1 \mathrm{~g}\right)$, ethyl acetate (EtOAc-; $\left.4 \mathrm{~g}\right)$, $n$-butanol (n-BuOH-; $277 \mathrm{~g}$ ) and $\mathrm{H}_{2} \mathrm{O}$-soluble fractions (14 g). The $\mathrm{CH}_{2} \mathrm{Cl}_{2-}$, EtOAc-, $n$ - $\mathrm{BuOH}$ - and $\mathrm{H}_{2} \mathrm{O}$-soluble layers were tested on the NO production inhibition assay. Amongst these, the EtOAc fraction demonstrated the most potent activity. Thus, this fraction ( $4 \mathrm{~g}$ ) was separated over a silica gel column $\left(\mathrm{CHCl}_{3}-\mathrm{MeOH}, 10: 1\right)$ to yield 14 fractions (AAE1-AAE14). Sub-fraction AAE1 (100 mg) was purified by preparative HPLC (40\% MeCN) to yield compound 1 (50 mg).

Compound 1, light yellow in color, showed ${ }^{1} \mathrm{H}-\mathrm{NMR}$ $\left(600 \mathrm{MHz}, \mathrm{DMSO}-d_{6}\right) \delta: 7.33\left(2 \mathrm{H}, \mathrm{s}, \mathrm{H}-2^{\prime}\right.$ and H-5'), $6.99(1 \mathrm{H}$, s, H-3), 6.56 (1H, d, J=2.1 Hz, H-8), 6.20 (1H, d, J=2.1 Hz, H-6), $3.88\left(6 \mathrm{H}, \mathrm{s}, 3^{\prime}\right.$ and $\left.5^{\prime}-\mathrm{OCH}_{3}\right){ }^{13} \mathrm{C}-\mathrm{NMR}\left(150 \mathrm{MHz}, \mathrm{DMSO}-d_{6}\right)$

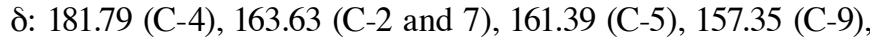
148.18 (C-3' and 5'), 139.84 (C-4'), 120.36 (C-1'), 104.33 (C-2' and 6'), 103.67 (C-10), 103.58 (C-3), 98.87 (C-6), 94.24 (C-8), 56.36 (C-3' and C-5', $-\mathrm{OCH}_{3}$ ), ESI-MS m/z 343.09[M-H]'.

Cell culture and MTS assay for cell viability. RAW 264.7 cells [Korean Cell Line Bank (KCLB); KCLB no. 40071] were cultured as previously described (23). Briefly, the cells were grown in RPMI-1640 medium supplemented with $10 \%$ heatinactivated fetal bovine serum (FBS; Gibco, Invitrogen, Carlsbad, CA, USA) and $1 \%$ penicillin-streptomycin. The cells were cultured at $37^{\circ} \mathrm{C}$ in a humidified $5 \% \mathrm{CO}_{2}$ incubator. The fractions and isolated compounds from A. aequalis were dissolved in dimethyl sulfoxide (DMSO) prior to their use in cell culture; the final concentrations of DMSO were $0.1 \%$ or less. DMSO $(0.1 \%, \mathrm{v} / \mathrm{v})$ was used as a control. The effects of the $\mathrm{EtOH}$ extract and bioactive compounds from A. aequalis on cell viability were determined by a 3-(4,5-dimethylthiazol-2-yl)5-(3-carboxymethoxyphenyl)-2-(4-sulfophenyl)-2H-tetrazolium, inner salt (MTS) assay (CellTiter 96 Aqueous One Solution; Promega, Madison, WI, USA), according to the manufacturer's instructions. Briefly, the cells were seeded in 96-well plates at a density of $3 \times 10^{5}$ cells/well, and $24 \mathrm{~h}$ after the cells were seeded, the extracts or their bioactive compounds were added. Following $2 \mathrm{~h}$ of incubation, a solution of MTS was added, and the absorbance at $490 \mathrm{~nm}$ was measured using a microplate reader (Infinite $200 \mathrm{PRO}$; Tecan, Grödig, Austria) to determine the formazan concentration.

Measurement of $N O$ production. Nitrite is a stable end-product of NO generated by activated macrophages. We measured the nitrite accumulation in the culture supernatant as an indicator of NO production (14). The RAW 264.7 cells were seeded in 12 -well plates at a density of $3 \times 10^{5}$ cells/well and incubated for $24 \mathrm{~h}$. The cells were treated with the extracts or its bioactive compounds for $1 \mathrm{~h}$ before LPS (500 $\mathrm{ng} / \mathrm{ml}$ ) was added to 
the cells. Following incubation for $24 \mathrm{~h}, 100 \mu \mathrm{l}$ of cell culture medium were mixed with an equal volume of Griess reagent [ $1 \%$ sulfanilamide in 5\% phosphoric acid, $0.1 \% \mathrm{~N}$-(1-naphthyl) ethylenediamine in $\mathrm{H}_{2} \mathrm{O}$ ] and incubated at room temperature for $10 \mathrm{~min}$. The absorbance was measured at $540 \mathrm{~nm}$ using an ELISA microplate reader (Infinite 200 PRO; Tecan). The nitrite concentrations were determined by extrapolation from a standard sodium nitrite curve.

Measurement of prostaglandin $E_{2}\left(P G E_{2}\right)$ production. The effect of the bioactive compound on the LPS-induced release of $\mathrm{PGE}_{2}$, a pro-inflammatory mediator, was determined. The RAW264.7 cells were seeded in 6 -well plates $\left(1 \times 10^{6}\right.$ cells/ well) and incubated for $24 \mathrm{~h}$. The cells were treated with the bioactive compounds $(5,10,50$ and $100 \mu \mathrm{g} / \mathrm{ml})$ for $1 \mathrm{~h}$ before LPS $(500 \mathrm{ng} / \mathrm{ml})$ was added to the cells. Following incubation for $18 \mathrm{~h}$, the concentrations of $\mathrm{PGE}_{2}$ in the conditioned culture medium were determined using the $\mathrm{PGE}_{2}$ EIA kit (R\&D systems, Minneapolis, MN, USA) according to the manufacturer's instructions.

Western blot analysis. The effects of the bioactive compounds on the expression of iNOS and COX-2 were examined. The RAW 264.7 cells were seeded in 6-well plates at a density of $1 \times 10^{6}$ cells/well, incubated for $24 \mathrm{~h}$ and then pre-treated with the bioactive compounds $(5,10,50$ and $100 \mu \mathrm{g} / \mathrm{ml})$ for $1 \mathrm{~h}$. Following stimulation with LPS $(500 \mathrm{ng} / \mathrm{ml})$ for $3 \mathrm{~h}$ in the presence of the bioactive compounds, the cells were collected and washed twice with cold phosphate-buffered saline (PBS). The cells were lysed in cold RIPA buffer ( $\mathrm{pH}$ 7.4) containing $20 \mathrm{mM}$ Tris- $\mathrm{HCl}$, $150 \mathrm{mM} \mathrm{NaCl}, 1 \mathrm{mM} \mathrm{Na}{ }_{2}$ EDTA, $1 \mathrm{mM}$ EGTA, $1 \%$ NP-40, $1 \%$ sodium deoxycholate, $2.5 \mathrm{mM}$ sodium pyrophosphate, $1 \mathrm{mM}$ b-glycerophosphate, $1 \mathrm{mM} \mathrm{Na} \mathrm{VO}_{4}$ and $1 \mathrm{lg} / \mathrm{ml}$ leupeptin. The cell lysates were centrifuged at $15,000 \mathrm{x} \mathrm{g}$ for $30 \mathrm{~min}$ at $4^{\circ} \mathrm{C}$. The protein concentrations were determined by the Bradford method (Bio-Rad, Richmond, CA, USA). Forty-five micrograms of protein were separated by $10 \%$ sodium dodecyl sulfate polyacrylamide gel electrophoresis and transferred onto PVDF membranes (Bio-Rad). The membranes were blocked with $5 \%$ skim milk in PBS containing 0.1\% Tween-20 (pH 7.2). The membranes were then incubated overnight with primary antibodies [iNOS (1:100; \#13120); COX-2 (1:5,000; \#4842); all from Cell Signaling Technology, Inc., Danvers, MA, USA] at $4^{\circ} \mathrm{C}$. After washing, the membranes were incubated with horseradish peroxidase-conjugated secondary antibodies (anti-rabbit $\lg \mathrm{G}$, 1:2,000; \#7074; all from Cell Signaling Technology, Inc.) for at least $1 \mathrm{~h}$ at room temperature. A band of interest was detected with an ECL system (Ab Frontier, Seoul, Korea) and the intensities were analyzed and quantified using a FluorChem densitometer and the ImageJ program (National Institute of Health, Bethesda, MD, USA).

Measurement of ROS production. Intracellular ROS production was measured using the cell-permeable fluorogenic probe, dichlorofluorescin diacetate (DCFH-DA). DCFH-DA is hydrolyzed to DCFH by a deacetylase within the cells and oxidized by a variety of intracellular ROS to DCF, a highly fluorescent compound. The cells were seeded in a $60-\mathrm{mm}$ culture dish at a density of $1.5 \times 10^{6}$ cells/dish and incubated for $24 \mathrm{~h}$. The cells were pre-treated with the bioactive compounds $(5,10,50$ and
$100 \mu \mathrm{g} / \mathrm{ml}$ ) for $1 \mathrm{~h}$. The cells were then treated with the bioactive compounds in the presence of LPS (500 ng/ml) for $18 \mathrm{~h}$. Following treatment, the cells were washed with $\mathrm{SF}$ medium and treated with $20 \mu \mathrm{M}$ DCFH-DA for $30 \mathrm{~min}$ at $37^{\circ} \mathrm{C}$ in a $\mathrm{CO}_{2}$ incubator. The DCFA level was measured using a flow cytometer (Cytomics FC500; Beckman Coulter, Brea, CA, USA).

Statistical analysis. Each experiment was performed at least in triplicate. All the values are expressed as the means \pm SD, and the data were analyzed using the SPSS 19.0 software. The data were analyzed by one-way ANOVA followed by Duncan's multiple range test to determine the differences among the treatment groups. P-values $<0.05$ were considered to indicate statistically significant differences.

\section{Results}

Effects of $\mathrm{MeOH}$ extract and 5 soluble fractions from A. aequalis on LPS-induced NO production. The RAW 264.7 cells were treated with various concentrations $(10,50,100,200$ and $500 \mu \mathrm{g} / \mathrm{ml}$ ) of the EtOH extract to test its cellular cytotoxicity. Cell viability was not significantly affected by the EtOH extract at a concentration of up to $200 \mu \mathrm{g} / \mathrm{ml}$, as determined by MTS assay (Fig. 1A). Thus, the cells were treated with the EtOH extract of $A$. aequalis at concentrations in the range of 0-200 $\mu \mathrm{g} / \mathrm{ml}$. The stimulation of RAW 264.7 cells with $500 \mathrm{ng} /$ $\mathrm{ml}$ LPS significantly increased NO production. The EtOH extract of A. aequalis inhibited the LPS-stimulated NO production in a dose-dependent manner $(\mathrm{p}<0.05)$, with a $33 \%$ inhibition observed at a concentration of $200 \mu \mathrm{g} / \mathrm{ml}$ (Fig. 2A). Among the soluble fractions, the EtOAc-soluble fraction was comparable to the $\mathrm{EtOH}$ extract at a concentration of $100 \mu \mathrm{g} / \mathrm{ml}$ (Fig. 2B).

Identification of isolated compounds from the anti-inflammatory soluble fraction. The most active EtOAc-soluble fraction was purified by reversed-phase chromatography, and one major compound was separated. The structure of the compound was identified as tricin through a comparison of the reported spectroscopic data. The chemical structure of the compound is illustrated in Fig. 3.

Effects of tricin isolated from A. aequalis on pro-inflammatory mediators. The RAW 264.7 cells were treated with tricin (10, 50,100 and $200 \mu \mathrm{g} / \mathrm{ml}$ ) to test its cellular cytotoxicity. Tricin did not significantly decrease cell viability (Fig. 1B). To confirm the anti-inflammatory activity of tricin, we examined the effect of tricin on LPS-induced NO production. The nitrite concentration decreased by $4.5,15.8,51.8$ and $72.0 \%$ following treatment with $5,10,50$ and $100 \mu \mathrm{g} / \mathrm{ml}$ tricin, respectively compared with the LPS-stimulated cells (Fig. 4A). The concentrations used in this study were based on other studies that examined the anti-inflammatory effects of tricin in RAW cells $(24,25)$. Thus, treatment with tricin inhibited NO production in a dose-dependent manner ( $<<0.05$; Fig. 4A). Tricin also inhibited the LPS-induced PGE $_{2}$ production in a dose-dependent manner $(\mathrm{p}<0.05)$. $\mathrm{PGE}_{2}$ production was decreased by $8.1,11.2,25.2$ and $35.6 \%$ in the cultures containing 5, 10, 50 and $100 \mu \mathrm{g} / \mathrm{ml}$ tricin, respectively (Fig. 4B).

Effect of tricin isolated from A. aequalis on the protein expression of $i N O S$ and $C O X-2$. We used western blot analysis 

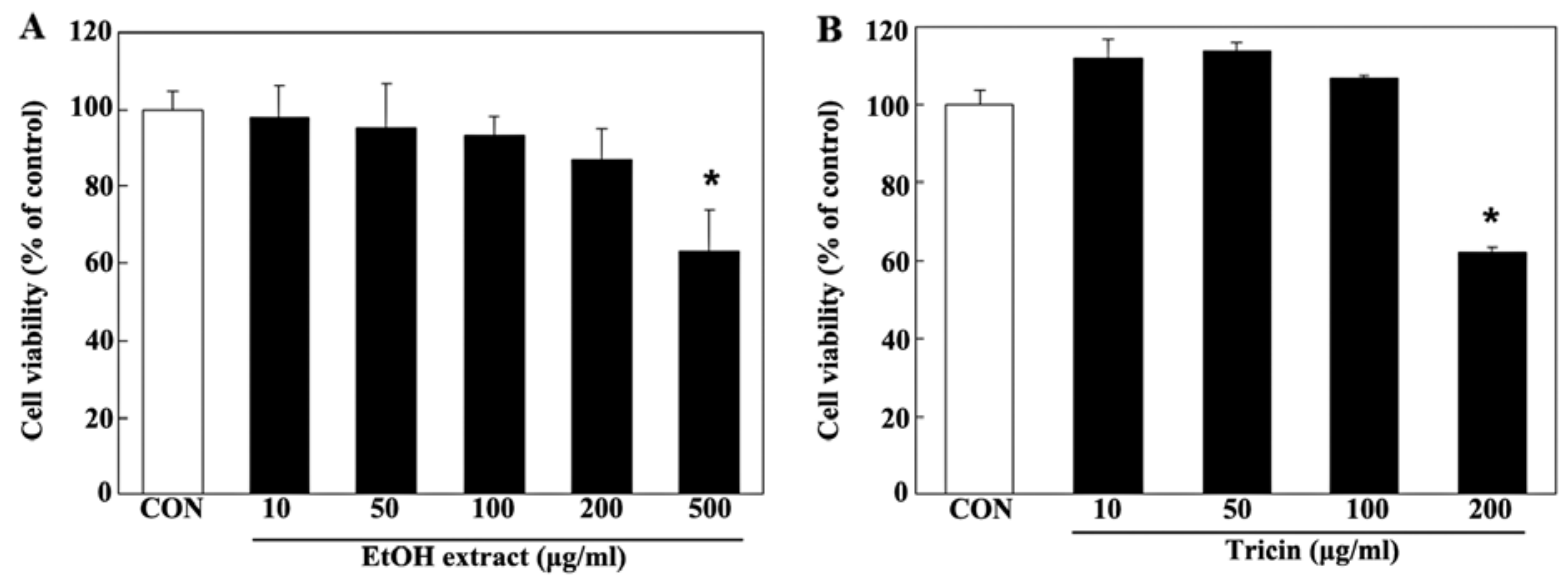

Figure 1. Effects of the ethanol (EtOH) extract and tricin on the viability of RAW 264.7 cells. The cells were treated with the indicated concentrations of EtOH extract and tricin for $48 \mathrm{~h}$, and cell viability was then measured. (A) EtOH extract and (B) Tricin. The data are presented as the means \pm SD from 3 independent experiments.

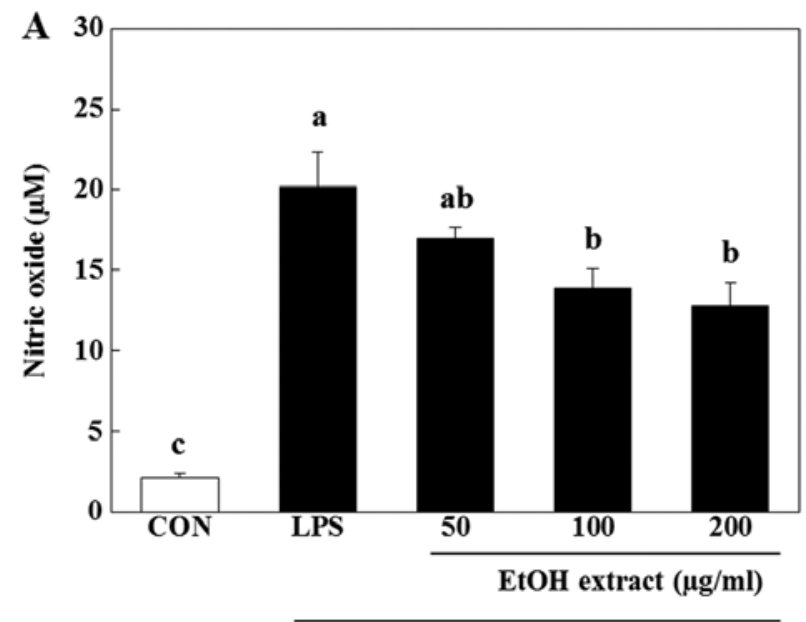

LPS (500 ng/ml)

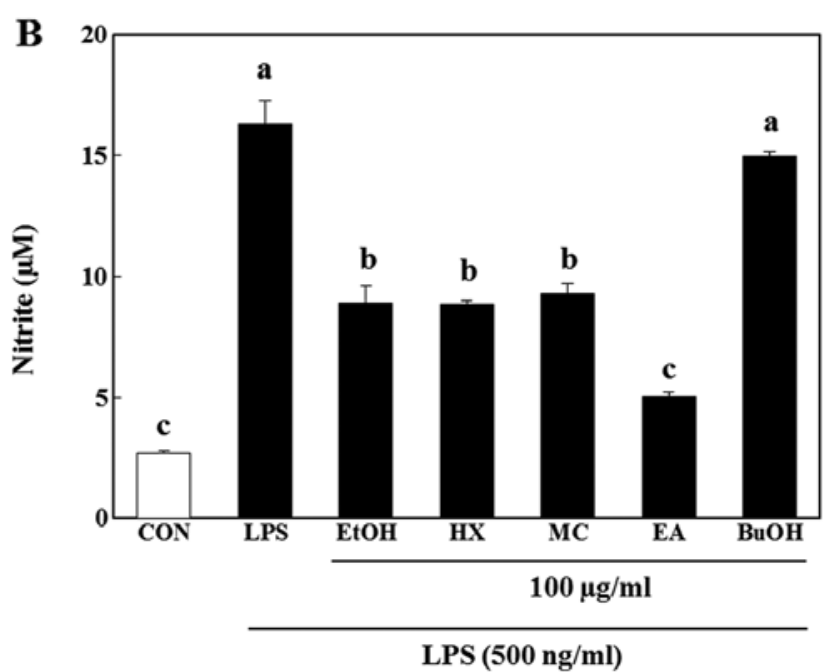

Figure 2. Effects of the ethanol (EtOH) extract and 4 soluble fractions from A. aequalis on lipopolysaccharide (LPS)-induced nitric oxide (NO) production in RAW 264.7 cells. The cells were treated with the indicated concentrations of EtOH extract or 4 fractions from A. aequalis for $1 \mathrm{~h}$ and then stimulated with LPS $(500 \mu \mathrm{g} / \mathrm{ml})$ for $18 \mathrm{~h}$. The levels of nitrite were measured in the culture medium using Griess reagent. (A) EtOH extract and (B) 4 soluble phases compared with the ethanol extract. The data are presented as the means \pm SD from 3 independent experiments. Bars labeled with the same letter indicates no significant differences; bars labeled with different letters indicates significant differences, as determined by one-way ANOVA followed by Duncan's test ( $<0.05$ ). CON, control (no treatment); $\mathrm{HX}, n$-hexane fraction; MC, dichloromethane fraction; EA, ethyl acetate fraction; $\mathrm{BuOH}, n$-butanol fraction.<smiles>COc1cc(-c2cc(=O)c3c(O)cc(O)cc3o2)cc(OC)c1O</smiles>

Figure 3. The structure of the compound isolated from the ethyl acetate fraction. to determine whether the inhibitory effect of tricin on NO production was related to the modulation of iNOS and COX-2 expression. The protein expression levels of iNOS and COX-2 were upregulated in response to LPS, and treatment with tricin markedly inhibited these increases ( $\mathrm{p}<0.05$; Fig. 5). The protein expression of iNOS was decreased by 49.4,57.0,94.0 and $96.2 \%$ in cultures containing 5,10,50 and $100 \mu \mathrm{g} / \mathrm{ml}$ of tricin, respectively ( $<<0.01 ;$ Fig. 5A). Similarly, treatment with tricin at 5, 10, 50 and $100 \mu \mathrm{g} / \mathrm{ml}$ suppressed COX-2 expression by as much as $4.7,20.3,38.8$ and $49.8 \%$, respectively (p<0.01; Fig. 5B).

Effect of tricin isolated from A. aequalis on ROS production. To investigate whether tricin influences ROS production, we measured ROS generation based on the DCF fluorescence 

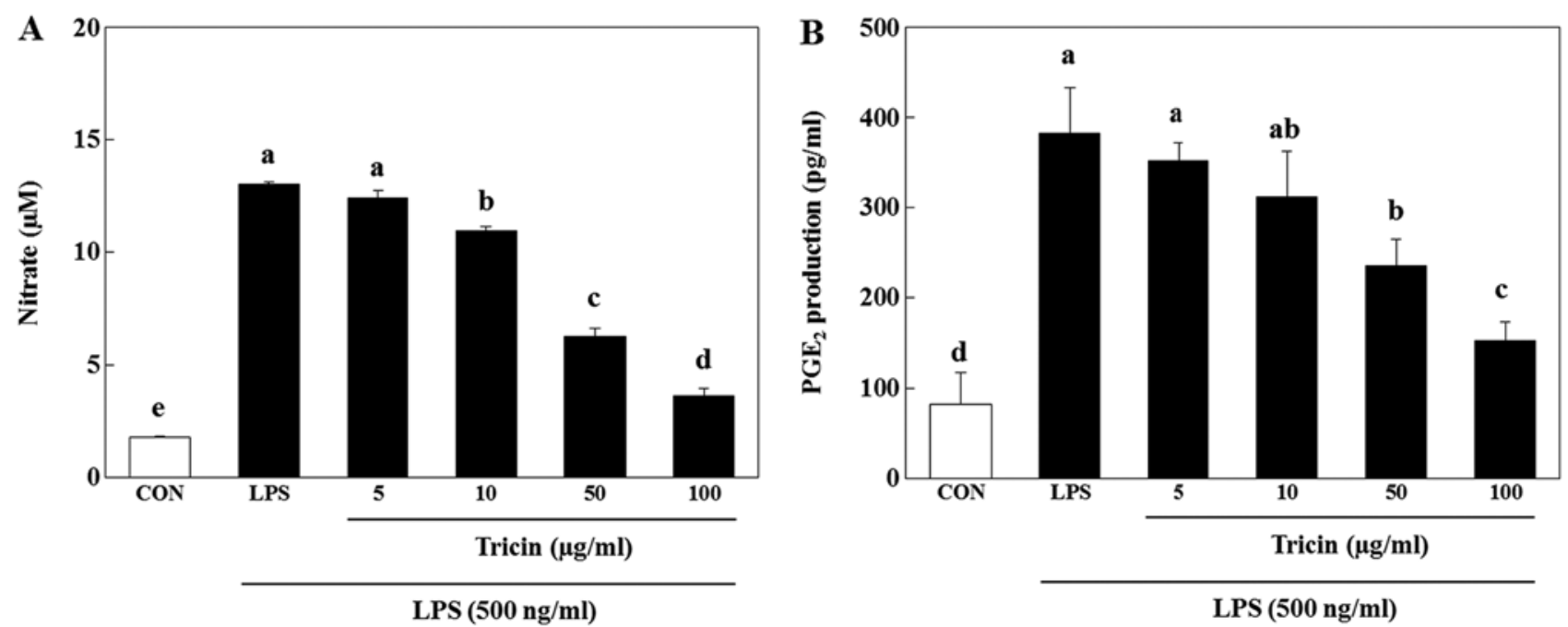

Figure 4. Effects of tricin isolated from A. aequalis extract on lipopolysaccharide (LPS)-induced nitric oxide (NO) and prostaglandin $\mathrm{E}_{2}\left(\mathrm{PGE}_{2}\right)$ production in RAW 264.7 cells. The cells were treated with the indicated concentrations of tricin for $1 \mathrm{~h}$ and then stimulated with LPS (500 $\mu \mathrm{g} / \mathrm{ml})$ for $18 \mathrm{~h}$. The levels of nitrite and $\mathrm{PGE}_{2}$ were measured in the culture media using (A) Griess reagent and (B) an EIA kit. The data are presented as the means \pm SD from 3 independent experiments. Bars labeled with the same letter indicates no significant differences; bars labeled with different letters indicates significant differences, as determined by one-way ANOVA followed by Duncan's test $(\mathrm{p}<0.05)$. CON, control (no treatment).
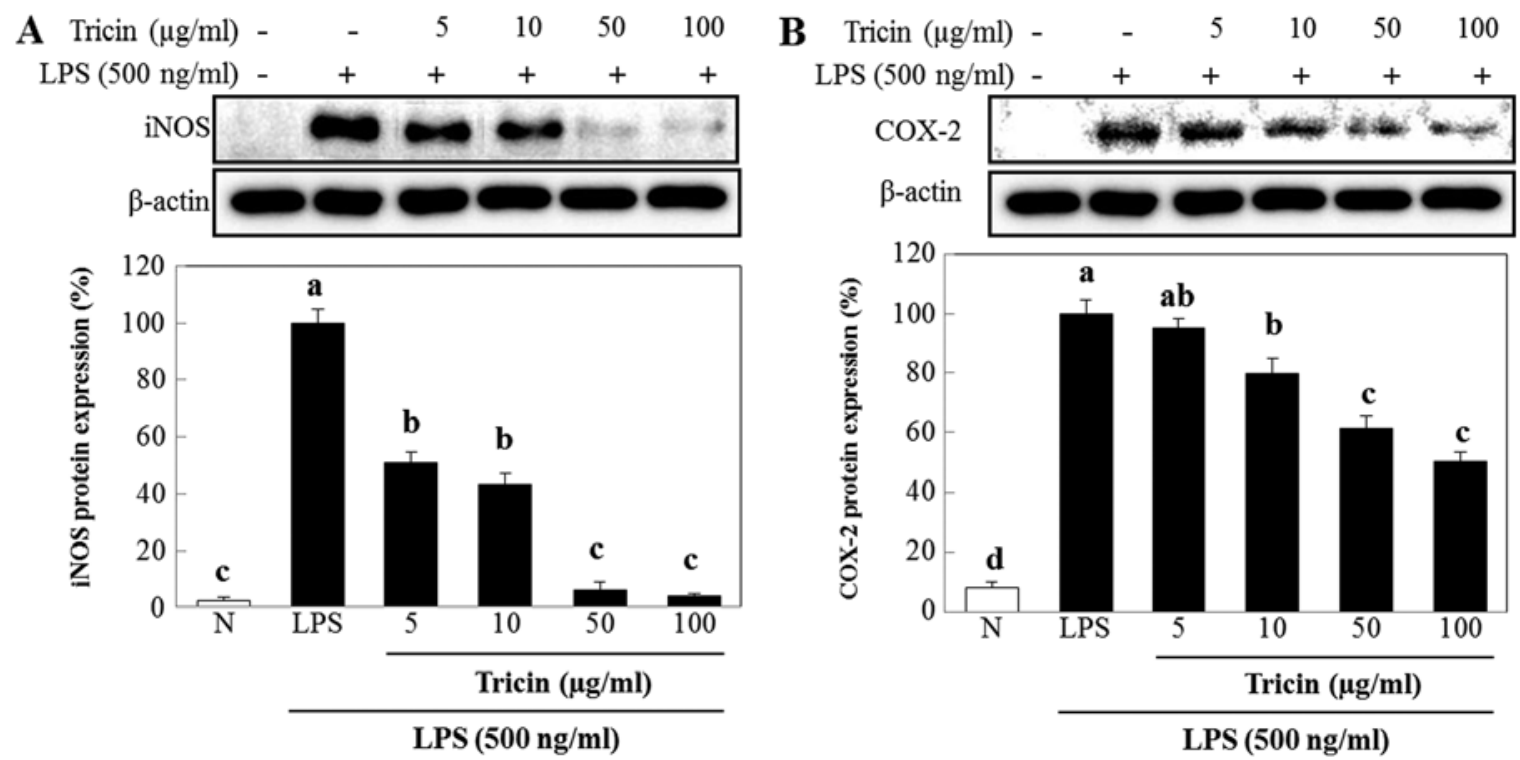

Figure 5. Effect of tricin isolated from A. aequalis extract on lipopolysaccharide (LPS)-induced expression of inducible nitric oxide synthase (iNOS) and COX-2. The cells were treated with the indicated concentrations of tricin for $1 \mathrm{~h}$ and then stimulated with LPS $(500 \mathrm{ng} / \mathrm{ml})$ for $18 \mathrm{~h}$. Western blot analysis was performed for the determination of the protein levels of iNOS and COX-2. (A and B) Western blot analyses of iNOS and COX-2. (A) Protein expression of iNOS. (B) Protein expression of COX-2. The data are presented as the means \pm SD from 3 independent experiments. Bars labeled with the same letter indicates no significant differences; bars labeled with different letters indicates significant differences, as determined by one-way ANOVA followed by Duncan's test ( $\mathrm{p}<0.05$ ). N, normal (untreated group).

intensity in LPS-stimulated RAW 264.7 cells. Exposure to LPS resulted in an increase in the DCF fluorescence intensity, and this increase decreased by treatment with tricin in a dose-dependent manner (p<0.05; Fig. 6). Decreases of 15.7, 34.5 and $75.3 \%$ were obtained with concentrations of 10,50 and $100 \mu \mathrm{g} / \mathrm{ml}$ tricin, respectively.

\section{Discussion}

A. aequalis has been traditionally used for the treatment of inflammatory ailments, such as rheumatic pain, wounds, ulcers and fever. Although the anti-inflammatory effects of A. aequalis ethanol extracts have been reported (23), the compounds responsible for these anti-inflammatory effects and the mechanisms involved have not yet been fully explored. Therefore, in this study, we isolated and determined the major anti-inflammatory compounds of the A. aequalis extract through activity-guided fractionation. We concluded that tricin is the active component of $A$. aequalis responsible for the observed anti-inflammatory effect.

In vitro assays to measure the inhibition of $\mathrm{NO}$ production were used to screen the active soluble phase and various 


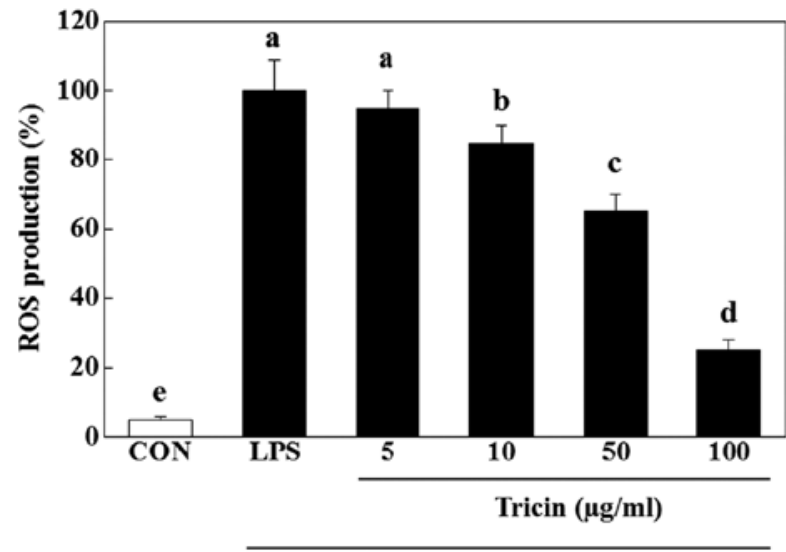

$\operatorname{LPS}(500 \mathrm{ng} / \mathrm{ml})$

Figure 6. Effects of tricin isolated from A. aequalis extract on lipopolysaccharide (LPS)-induced ROS production in RAW 264.7 cells. The cells were treated with the indicated concentrations of tricin for $1 \mathrm{~h}$ and then stimulated with LPS $(500 \mathrm{ng} / \mathrm{ml})$ for $18 \mathrm{~h}$. Intracellular peroxide was determined by labeling with DCFH-DA for $30 \mathrm{~min}$, and the fluorescent intensity was analyzed using a flow cytometer. Bars labeled with the same letter indicates no significant differences; bars labeled with different letters indicates significan differences, as determined by one-way ANOVA followed by Duncan's test $(\mathrm{p}<0.05)$. CON, control (no treatment).

compounds isolated from the A. aequalis extract. NO is a major well-known pro-inflammatory mediator, and the excess production of NO is one of the characteristics of inflammation, such as autoimmune disease and septic shock (26). It is known that NO contributes to the inflammatory cascade by increasing vascular permeability and the extravasation of fluids and proteins at inflammatory sites $(27,28)$. For these reasons, the suppression of NO production has been emphasized as a pharmaceutical strategy for the treatment of inflammatory diseases (29). In this study, we confirmed the anti-inflammatory effect of $A$. aequalis ethanol extracts (23), by the inhibition of NO production in LPS-stimulated RAW 264.7 cells, which is consistent with the results of previous studies. In the following experiment, we compared the ability of the EtOH extract and its four solvent-soluble fractions to inhibit LPS-induced NO production, and the bioassay-guided purification resulted in the isolation of one compound, namely tricin. Tricin is a flavonoid, is found ubiquitously in plants, but there has been no report on the biological activity of tricin isolated from A. aequalis.

In this study, the analysis of compound 1 isolated from the most effective EtOAc fraction revealed that the amount of tricin was higher than that of the other compounds. Moreover, tricin significantly suppressed NO production in LPS-stimulated RAW 264.7 cells. These results indicate that tricin is a major anti-inflammatory compound in A. aequalis EtOAc extract.

The inhibitory effect of the EtOH extract of A. aequalis and tricin on NO production was not due to treatment cytotoxicity as the concentrations that suppressed NO production did not affect cell viability, as determined by MTS assay. NO is synthesized from L-arginine by the three major NOS isoforms, namely neuronal NOS (nNOS), endothelial NOS (eNOS) and iNOS. Although the constitutive isoforms (nNOS and eNOS) controlled by $\mathrm{Ca}^{2+} /$ calmodulin produce small amounts of $\mathrm{NO}$, iNOS produces markedly higher amounts of $\mathrm{NO}$ and is expressed only during inflammation (30). iNOS is highly induced by various inflammatory stimuli, such as bacterial LPS and inflammatory cytokines, in macrophages $(31,32)$. As iNOS inhibitors attenuate various chronic inflammatory diseases, the inhibition of iNOS expression has significant meaning as a therapeutic target for inflammation-related disease. It has been reported that the A. aequalis extract suppresses the expression and activity of iNOS in LPS-stimulated RAW264.7 cells. In this study, we found that tricin isolated from A. aequalis extract inhibited the protein expression of iNOS. These results suggest that tricin inhibits NO production in LPS-induced RAW 264.7 cells by suppressing iNOS expression. $\mathrm{PGE}_{2}$ is also an important mediator in inflammatory diseases, such as rheumatic arthritis and osteoarthritis, by promoting local vasodilation and local attraction and activating neutrophils, macrophages and mast cells at the early stages of inflammation (33). $\mathrm{PGE}_{2}$ is produced by the enzyme, COX-2, in response to inflammatory stimuli. Lowering the production of $\mathrm{PGE}_{2}$ by the inhibition of COX-2 is another therapeutic approach to suppress the inflammatory response. In this study, we demonstrated that tricin contributed to the inhibitory effect of the A. aequalis extract on $\mathrm{PGE}_{2}$ production and COX-2 expression.

Tricin has been characterised by the Oryza sativa species (34). Tricin has been proposed to have anti-viral, immunomodulatory, anti-tubercular, anti-ulcerogenic, anti-mutagenic, mildly estrogenic, chemopreventive, antioxidant and potent anticancer effects $(24,25,35-38)$. In this study, the exposure of RAW 264.7 cells to LPS resulted in an accumulation of intracellular peroxide. Tricin significantly attenuated the LPS-induced intracellular ROS increase. These results suggest that the inhibition of NO production by A. aequalis extract is, at least in part, related to the antioxidant activity of $A$. aequalis. Our study was limited in that a single cell line was used and we did not use an in vivo model. In addition, we did not investigate the hexane fraction, the second effective fraction, which was comparable to the EtOH extract. However, to the best of our knowledge, this study provides the first demonstration of the compounds responsible for the anti-inflammatory activity of A.aequalis.

Finally, our obtained data suggested that tricin could be considered as a lead compound for the development of agents against NO production. Moreover, the caffeoylglycerol ester-enrich extracts from the leaf and stem of A. aequalis may be applied as supplemental and/or functional foods having a beneficial effect against inflammation as well.

\section{Acknowledgements}

This study was supported by the Jeollanamdo Development Institute of Traditional Korean Medicine, Research Fund 2014.

\section{References}

1. Lee TB: Colored Flora of Korea. Hyangmunsa, p501, 1980.

2. Park SH: Unrecorded naturalized plants of Korea. Korean J Pl Taxon 23: 464-468, 2009.

3. Ahn DJ, Park SG, Son CK, Kim CR and Choi BS: Growth characteristics and yield of wheat as affected by sowing methods of seed broadcasting over rice plants and rotavating after seed broadcasting. J Crop Sci 39: 20-26, 1997.

4. Kim DH, Son BY, Kim SK, Shon GM and Kang DJ: Effect of over-sowing for labor-saving and on growth response as affected by different barley and wheat. J Crop Sci 38: 106-116, 1996.

5. Chin MS, Park CS and Ham YS: Ecological analysis of the water foxtail (Alopecurus aequalis) damage in barley cultivation on drained paddy fields. J Crop Sci 19: 157-170, 1977. 
6. Kim DH, Kim SK, Kim ES, Son BY and Kang DJ: Weed occurrence and control in simultaneous wheat sowing culture with rice harvest under no-tilled paddy field. Korean J Weed Sci 18: 186-190, 1998

7. Jung JS, Lee JS, Choi CD and Cheung JD: A study on sod culture using water foxtail (Alopecurus aequalis) in apple orchard. Kor J Weed Sci 18: 128-135, 1998.

8. Seong KY, Park TS, Cho HS, Seo MC and Jeon WT: Weed occurrence according to the density of water foxtail in No-tillage seeding rice paddy fields. Kor J Weed Sci 32: 280-284, 2012

9. State Administration of Traditional Chinese medicine (SATC): The encyclopedia of oriental herbal medicine. State Adm Tradit Chinesemedicine Shanghai China 8: 7393-7394, 1999.

10. Cho W, Nam JW, Kang HJ, Windono T, Seo EK and Lee KT: Zedoarondiol isolated from the rhizoma of Curcuma heyneana is involved in the inhibition of iNOS, COX-2 and pro-inflammatory cytokines via the downregulation of NF-kappaB pathway in LPS-stimulated murine macrophages. Int Immunopharmacol 9 : 1049-1057, 2009

11. Willoughby DA: Heberden Oration, 1974. Human arthritis applied to animal models. Towards a better therapy. Ann Rheum Dis 34: 471-478, 1975.

12. Dobrovolskaia MA and Vogel SN: Toll receptors, CD14, and macrophage activation and deactivation by LPS. Microbes Infect 4: 903-914, 2002.

13. McDaniel ML, Kwon G, Hill JR, Marshall CA and Corbett JA Cytokines and nitric oxide in islet inflammation and diabetes. Proc Soc Exp Biol Med 211: 24-32, 1996.

14. KimDH,Park SJ,Jung JY,Kim SC andByun SH: Antiinflammatory effects of the aqueous extract of Hwangnyenhaedok-tang in LPS-activated macrophage cells. Korean J Herbology 24: 47-39, 2009.

15. Willeaume V, Kruys V, Mijatovic T and Huez G: Tumor necrosis factor-alpha production induced by viruses and by lipopolysaccharides in macrophages: Similarities and differences. J Inflamm 46: 1-12, 1995-1996.

16. Moncada S and Higgs EA: Endogenous nitric oxide: Physiology, pathology and clinical relevance. Eur J Clin Invest 21: 361-374, 1991.

17. Kim YO, Lee SW, Sohn SH, Kim SY, Oh MS and Kim SK: Anti-inflammatory effects of water extract of Eucommia ulmoides oliver on the LPS-induced RAW 264.7 cells. Hanguk Yakyong Changmul Hakhoe Chi 20: 381-386, 2012.

18. McCartney-Francis N, Allen JB, Mizel DE, Albina JE, Xie QW Nathan CF and Wahl SM: Suppression of arthritis by an inhibitor of nitric oxide synthase. J Exp Med 178: 749-754, 1993.

19. Feng GJ, Goodridge HS, Harnett MM, Wei XQ, Nikolaev AV, Higson AP and Liew FY: Extracellular signal-related kinase (ERK) and p38 mitogen-activated protein (MAP) kinases differentially regulate the lipopolysaccharide-mediated induction of inducible nitric oxide synthase and IL-12 in macrophages: Leishmania phosphoglycans subvert macrophage IL-12 production by targeting ERK MAP kinase. J Immunol 163 . 6403-6412, 1999.

20. Anest V, Hanson JL, Cogswell PC, Steinbrecher KA, Strahl BD and Baldwin AS: A nucleosomal function for IkappaB kinasealpha in NF-kappaB-dependent gene expression. Nature 423 659-663, 2003

21. Bohuslav J, Kravchenko VV, Parry GC, Erlic JH, Gerondakis S, Mackman N and Ulevitch RJ: Regulation of an essential innate immune response by the p50 subunit of NFkappaB. J Clin Invest 102: $1645-1652,1998$.
22. Beinke S and Ley SC: Functions of NF-kappaB1 and NF-kappaB2 in immune cell biology. Biochem J 382: 393-409, 2004.

23. Jung HK, Kang BM, Jang JH, Ahn BK, Yeo JH, Jung WS Cho JH, Kuk YI, Kyun KH and Cho HW: Inhibitory effect of Alopecurus aequalis Sobol ethanol extracts on LPS-induced inflammatory response in RAW 264.7 cells. Hanguk Yakyong Changmul Hakhoe Chi 22: 98-104, 2014.

24. Zhou J and Ibrahim RK: Tricin-a potential multifunctional nutraceutical. Phytochem Rev 9: 413-424, 2010.

25. Cai H, Al-Fayez M, Tunstall RG, Platton S, Greaves P, Steward WP and Gescher AJ: The rice bran constituent tricin potently inhibits cyclooxygenase enzymes and interferes with intestinal carcinogenesis in ApcMin mice. Mol Cancer Ther 4: 1287-1292, 2005

26. MacMicking JD, Nathan C, Hom G, Chartrain N, Fletcher DS, Trumbauer M, Stevens K, Xie QW, Sokol K, Hutchinson N, et al: Altered responses to bacterial infection and endotoxic shock in mice lacking inducible nitric oxide synthase. Cell 81: 641-650, 1995.

27. Guzik TJ, Korbut R and Adamek-Guzik T: Nitric oxide and superoxide in inflammation and immune regulation. J Physiol Pharmacol 54: 469-487, 2003.

28. Moncada S, Palmer RM and Higgs EA: Nitric oxide: Physiology, pathophysiology, and pharmacology. Pharmacol Rev 43: 109-142, 1991.

29. TsaoLT, TsaiPS,Lin RH,Huang LJ,Kuo SC and Wang JP: Inhibition of lipopolysaccharide-induced expression of inducible nitric oxide synthase by phenolic (3E)-4-(2-hydroxyphenyl)but-3-en-2-one in RAW 264.7 macrophages. Biochem Pharmacol 70: 618-626, 2005.

30. Lowenstein CJ and Padalko E: iNOS (NOS2) at a glance. J Cell Sci 117: 2865-2867, 2004.

31. Levy D, Höke A and Zochodne DW: Local expression of inducible nitric oxide synthase in an animal model of neuropathic pain. Neurosci Lett 260: 207-209, 1999.

32. Guastadisegni C, Nicolini A, Balduzzi M, Ajmone-Cat MA and Minghetti L: Modulation of PGE(2) and TNFalpha by nitric oxide and LPS-activated RAW 264.7 cells. Cytokine 19: 175-180, 2002.

33. Kalinski P: Regulation of immune responses by prostaglandin $E_{2}$. J Immunol 188: 21-28, 2012.

34. Mohanlal S, Parvathy R, Shalini V, Helen A and Jayalekshmy A: Isolation, characterization and quantification of tricin and flavonolignans in the medicinal rice Njavara (Oryza sativa L.), as compared to staple varieties. Plant Foods Hum Nutr 66: 91-96, 2011.

35. Havsteen B: Flavonoids, a class of natural products of high pharmacological potency. Biochem Pharmacol 32: 1141-1148, 1983.

36. Verschoyle RD, Greaves P, Cai H, Borkhardt A, Broggini M, D'Incalci M, Riccio E, Doppalapudi R, Kapetanovic IM, Steward WP and Gescher AJ: Preliminary safety evaluation of the putative cancer chemopreventive agent tricin, a naturally occurring flavone. Cancer Chemother Pharmacol 57: 1-6, 2006.

37. Oyama T, Yasui Y, Sugie S, Koketsu M, Watanabe K and Tanaka T: Dietary tricin suppresses inflammation-related colon carcinogenesis in male Crj: CD-1 mice. Cancer Prev Res (Phila) 2: 1031-1038, 2009.

38. Chang CL, Wang GJ, Zhang LJ, Tsai WJ, Chen RY, Wu YC and Kuo YH: Cardiovascular protective flavonolignans and flavonoids from Calamus quiquesetinervius. Phytochemistry 71: 271-279, 2010. 